\title{
TRAUMATIC SCAPHO LUNATE DISSOCIATION - A CASE REPORT
}

\section{B. Suresh Gandhi'1, G. Ramkumar², K. Kalaivanan², V. Karthi Sundar ${ }^{4}$}

\section{HOW TO CITE THIS ARTICLE:}

B. Suresh Gandhi, G. Ramkumar, K. Kalaivanan, V. Karthi Sunder. "Traumatic Scapho Lunate Dissociation - A Case Report". Journal of Evolution of Medical and Dental Sciences 2014; Vol. 3, Issue 07, February 17; Page: 1769-1773, DOI: $10.14260 /$ jemds/2014/2056

\begin{abstract}
Scapholunate dissociation is the most common carpal instability. We are presenting an interesting case of a $24 \mathrm{yr}$ old male with scapholunate instability following trauma. Appropriate investigations were done and surgical intervention was done on the same day. The ruptured ligaments were repaired and bony components scapholunate and scaphocapitate were corrected and fixed. Patient was immobilized in plaster for 8 weeks following which active mobilization exercises were started. The functional results were excellent and we have reported them using the mayo wrist score.
\end{abstract}

KEYWORDS: Slac wrist, scaphoid shift test, terry Thomas sign, scaphoid ring sign, scapholunate angle and capitolunate angle, Mayo wrist score.

INTRODUCTION: The Scapholunate dissociation is an injury to ligaments in the wrist that can lead to loosening of carpal bones. The risk factors are Ulna minus configuration, slope of radial articular surface and Lunotriquetral coalition. The main pathology is rotatory subluxation of the Scaphoid bone.

CASE REPORT: Mr. Panner Selvam 24yr male residing in Papparapakam working in Hyundai Company presented to the Orthopedic OPD on 31/8/12 with c/o pain swelling and inability to use the right wrist joint and hand. Patient gave a $\mathrm{H} / \mathrm{O}$ fall of a machine following which he developed the above said complaints. There were no relevant past medical and surgical histories.

Clinical examination revealed a diffuse swelling of the wrist and hand, grip strength weakness and absolutely no movement was present. Tenderness of the carpus and point tenderness at the scapholunate interval distal to listers tubercle were positive. Scaphoid shift test revealed the presence of scapholunate instability. Radial pulse+ active finger movements+ and no DNVD.

Routine blood investigations were normal. X ray of the wrist joint anteroposterior and lateral views showed terry Thomas sign gap between scaphoid and lunate $4 \mathrm{~mm}$ normal (1-2mm). Scaphoid ring sign which is progressive flexion and foreshortening of the scaphoid was also seen. Lateral view showed scapholunate angle of 80 degrees normal (30-60) and capitolunate angle of 40 degrees normal (20). The capitate was found to be lying in between scaphoid and lunate. The above findings strongly suggest scapholunate instability.

Preoperative evaluation was done and patient was posted for surgery. Under supraclavicular block through dorsal approach scaphoid and lunate were exposed. By progressive flexion and extension of the wrist we could see the capitate moving in and out. Two k wires of size $1.2 \mathrm{~mm}$ each were passed one to fix the scaphoid and lunate the other to fix the scaphoid and capitate. The palmar scaphotrapezoid ligament, radio scapholunate, radioscaphocapitate and anterior and posterior aspects of scapholunate interosseus ligaments were repaired. Post operatively the wrist was 
immobilized in neutral position in an above elbow thumb spica for 8 weeks following which the wires were removed and active mobilization exercises for the wrist joint was started. Periodical $\mathrm{x}$ rays were taken during the period of immobilization to check the position of wires which were satisfactory. Range of movements at the end of three months was dorsiflexion 0-55degrees, palmar flexion 0-55 degrees, radial deviation0-20degrees, ulnar deviation0-25degrees. At the end of six months we were able to achieve full range of movement dorsiflexion0-90degrees, palmarflexion0-90degrees, radial deviation0-35degrees, and ulnar deviation0-40degrees. At the end of one and half years the same results were maintained. (Figures 1-9).

DISCUSSION: Scapholunate instability is associated with increased scaphoid flexion and pronation with lunate extension. The abnormal articulation causes increased concentration of load leading to the development of degenerative arthritis. Scapholunate advanced collapse (SLAC) is a type of arthritis related to scapholunate dissociation. Wrick JD et al performed proximal row carpectomy for SLAC and were successful in preserving joint motion ${ }^{1}$. Our goals of surgical reconstruction were to relieve pain, restore mobility, improve grip, strength and to prevent degenerative arthritis.

Our case of scapholunate dissociation was an isolated entity. It can also occur as sequelae of perilunate dislocation. A partial injury of anterior aspect of scaholunate interosseus ligament could result in instability. The posterior aspect of the ligament can also be the main mechanical component. S J Svobodaet al took autografts from the foot for reconstruction of scaholunate interosseus ligament ${ }^{2}$. Lavernia $\mathrm{CJ}$ et al treated scapholunate dissociation by ligamentous repair and capsulodesis ${ }^{3}$. Shin SS et al treated using retinaculum bone autografts ${ }^{4}$. In our case both aspects were injured and hence the instability being very prominent. The rotatory subluxation of the scaphoid is being prevented by palmar scaphotrapezoid ligament. This problem was also addressed in our case. Watson HK et al did limited triscaphoid intercarpal ortho disease for rotatory subluxation of scaphoid 5 .

The advantage of surgical intervention at the earliest is that we can identify the ruptured ligaments easily and repair them. Bony components also were easily reduced and fixed with K wires. Marco Rosati et al treated the patients with bone anchors ${ }^{6}$. Delayed intervention has its own problems and complications. If the condition becomes chronic reconstructive procedures like dorsal capsulodesis, tendon weaves using free tendon grafts, scapholunate arthrodesis and bone ligament bone autografs have to be performed. None of the above said procedures have promising results. We might have to face complications like carpal collapse carpal disintegration and nonunion. Izge Gunal et al has seen scapholunate dissociation associated with distal radius fractures ${ }^{7}$. In our case there was no distal radius fracture. Davis et al did reconstruction of scapholunate model in a cadaver model using a bone ligament bone autograft from the foot ${ }^{8}$. Garcia et al used three ligament tenodesis for the treatment of scapholunate dissociation without secondary osteoarthritis ${ }^{9}$.

We have used the MAYO wrist score to assess the functional outcome in our case. It has four components to be looked for viz pain intensity, range of motion, grip strength and functional status. Our score was $80 \%$ normal $60-100 \%$. The patient is now able to do all his daily routine activities as well as his professional work.

CONCLUSION: Scapholunate dissociation when intervened early surgically gives good results as presented in our case. Later the intervention gives rise to several complications. Although several 
surgical procedures have been documented for later intervention none of them have given promising results.

\section{REFERENCES:}

1. Wyrick JD, Stern PJ, Kiefhaber TR. Motion-preserving procedures in the treatment of scapholunate advanced collapse wrist: proximal row carpectomy versus four-corner arthrodesis. J Hand Surg Am. 1995 Nov; 20(6):965-70.

2. S J Svoboda; W A Eglseder; S M Belkoff. Autografts from the foot for reconstruction of the scapholunate interosseous ligament. The Journal of hand surgery 1995; 20(6):980-5.

3. Lavernia CJ, Cohen MS, Taleisnik J. Treatment of scapholunate dissociation by ligamentous repair and capsulodesis. J Hand Surg. 1992;17A:354-359

4. Shin SS; Moore DC; Mcgovern RD; Weiss APC. Scapholunate Ligament Reconstruction Using A Bone-Retinaculum-Bone Autograft - A Biomechanic And Histologic-Study. The Journal of hand surgery23A (2), 1998, pp. 216-221.

5. Watson HK, Ryu J, Akelman E: Limited Triscaphoid Intercarpal Arthrodesis for Rotary Subluxation of the Scaphoid. J Bone Joint Surg 68(A): 345-349, March 1986

6. Marco Rosati; Piero Parchi; Matilde Cacianti; Andrea Poggetti; Paolo Domenico Parchi. Treatment of acute scapholunate ligament injuries with bone anchor. Musculoskeletal surgery 2010; 94(1):25-32.

7. Izge Gunal; Cemal Kazimoglu; Dinc Ozaksoy; Ismail Safa Satoglu; Taskin Altay; Muhittin Sener. Scapholunate dissociation associated with distal radius fractures. European journal of orthopaedic surgery \& traumatology: orthopédie traumatologie 2013; 23(8):877-81.

8. Davis, C. A, Culp, R. W, Hume, Eric L, Osterman, A L. Reconstruction of the scapholunate ligament in a cadaver model using a bone-ligament-bone autograft from the foot. Journal of Hand Surgery American Volum. 23:884-892. 1998

9. Garcia-Elias M, Lluch AL, Stanley JK. Three-ligament tenodesis for the treatment of scapholunate dissociation: indications and surgical technique. J Hand Surg Am. 2006 Jan; 31(1):125-34.

\section{FIG. 1: PREOPERATIVE X RAY}

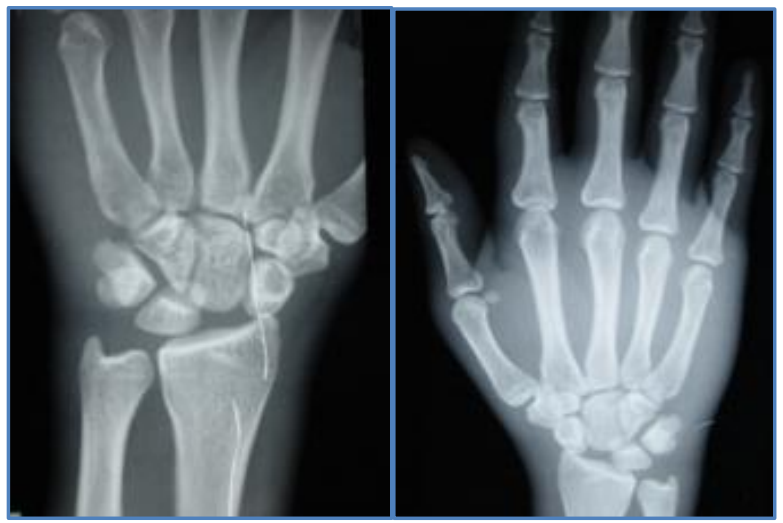

ANTEROPOSTERIOR VIEWS

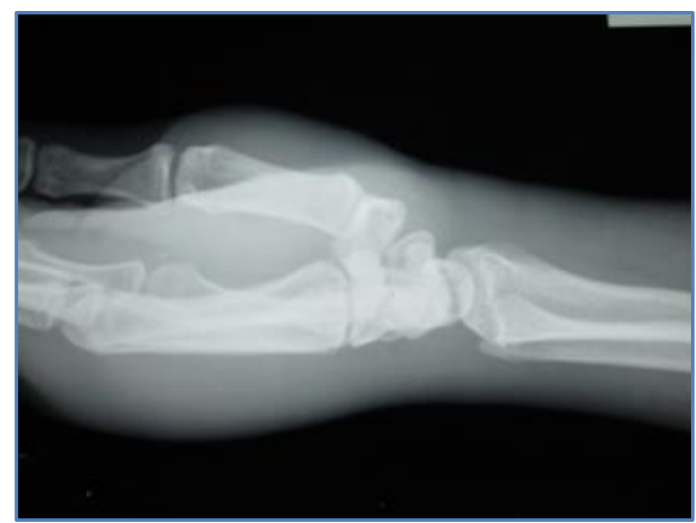

LATERAL VIEW 


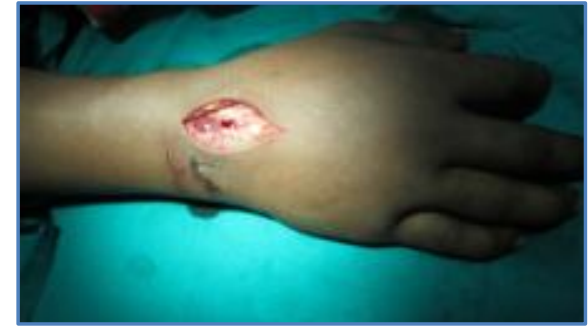

FIG. 2: INCISION

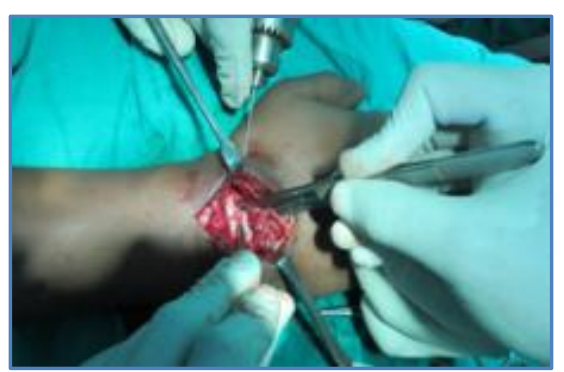

FIG. 4: BONY FRAGMENTS FIXED WITH K WIRES

FIG. 5: POST OP X-RAY
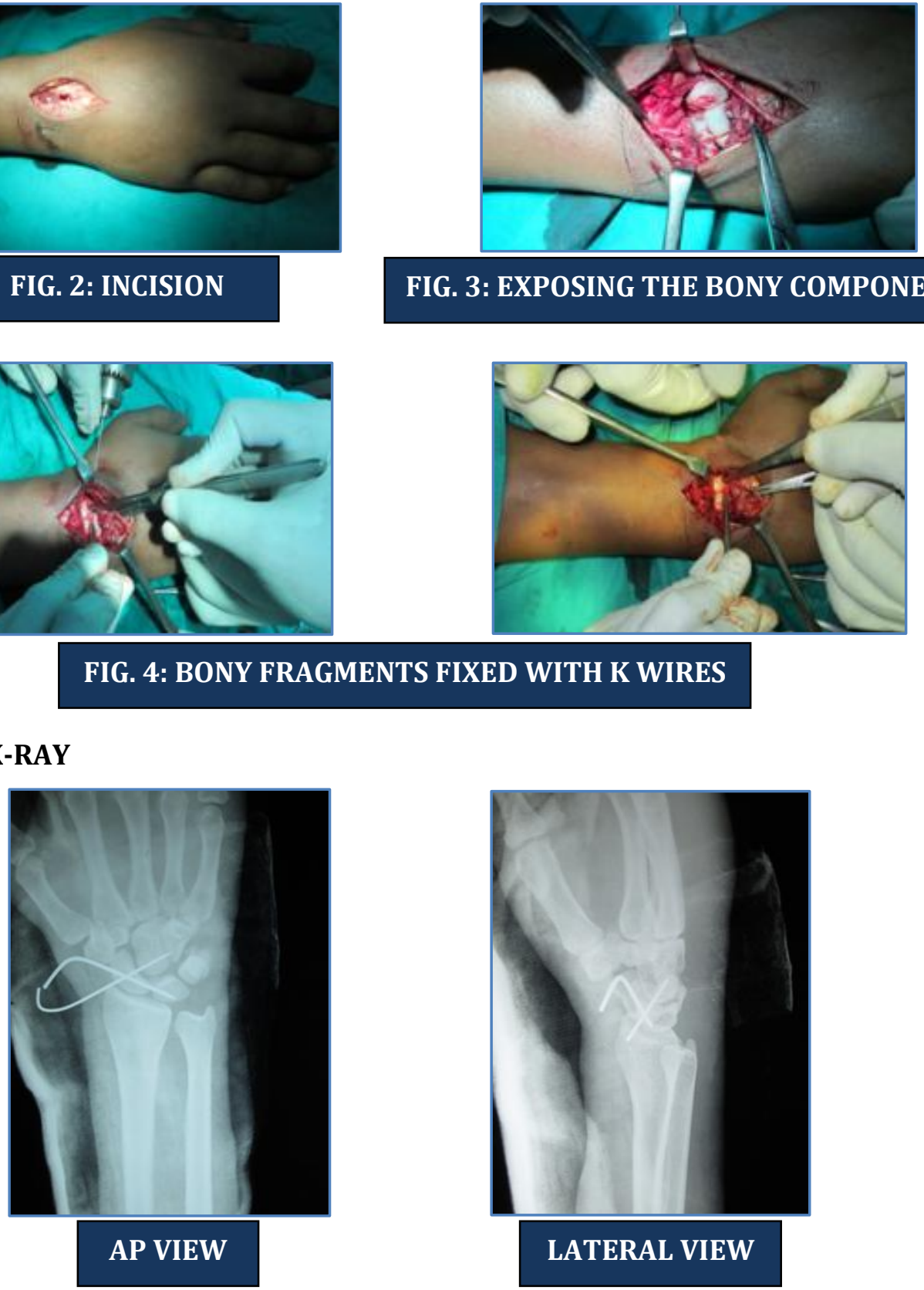

FIG. 3: EXPOSING THE BONY COMPONENTS

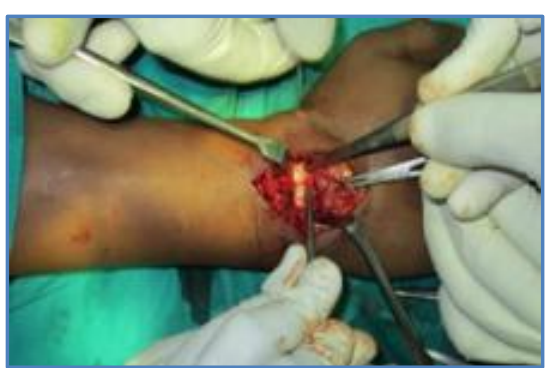

\section{SS}

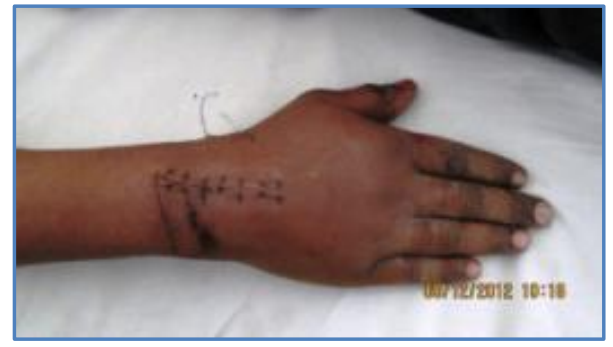

FIG. 6: CLOSURE 


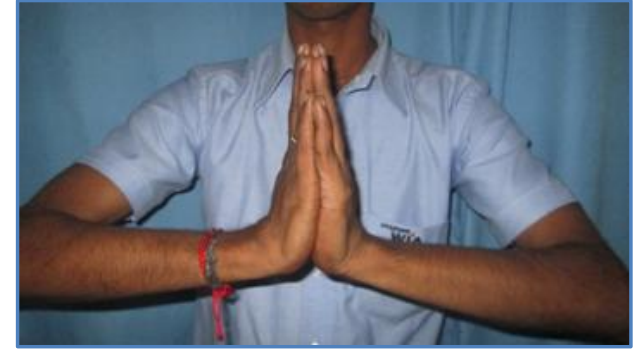

FIG. 7: DORSIFLEXION - FULL RANGE

FIG. 9: POST OP - ONE AND HALF YEARS

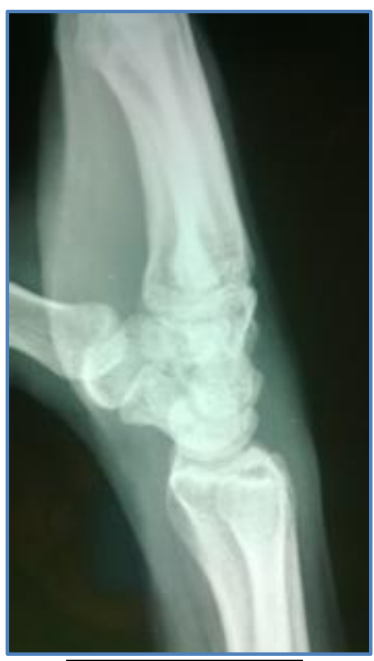

AP VIEW

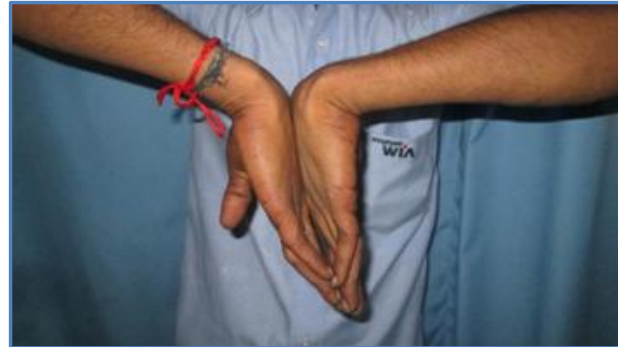

FIG. 8: PALMAR FLEXION

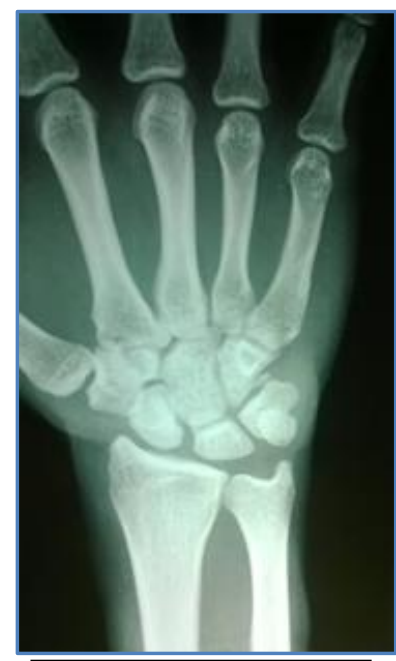

LATERAL VIEW

\section{AUTHORS:}

1. B. Suresh Gandhi

2. G. Ramkumar

3. K. Kalaivanan

4. V. Karthi Sundar

\section{PARTICULARS OF CONTRIBUTORS:}

1. Assistant Professor, Department of Orthopedics, Saveetha Medical College, Chennai.

2. Associate Professor, Department of Orthopedics, Saveetha Medical College, Chennai.

3. Assistant Professor, Department of Orthopedics, Saveetha Medical College, Chennai.
4. Assistant Professor, Department of Orthopedics, Saveetha Medical College, Chennai.

\section{NAME ADDRESS EMAIL ID OF THE} CORRESPONDING AUTHOR:

Dr. B. Suresh Gandhi,

No. 5, Cauvery Cross Street, Devi Nagar, RCC Post,

Annanoor, Chennai - 600109,

Tamilnadu, India.

E-mail:bsg.ortho@gmail.com

Date of Submission: 27/01/2014.

Date of Peer Review: 28/01/2014.

Date of Acceptance: 05/02/2014.

Date of Publishing: 15/02/2014. 